\title{
Comparative Analysis on English Websites of Chinese and Foreign Multinational Construction Companies
}

\author{
Fei Han ${ }^{1, *}$, Sheng Peng ${ }^{2, *}$, Dianlei Geng ${ }^{2}$, Hongbo Song ${ }^{2}$, Yunfei $\mathrm{Han}^{3}$ and Kai \\ Huang ${ }^{1}$
}

\author{
${ }^{1}$ Wuhan College of Arts and Science \\ ${ }^{2}$ Wuhan University of Science and Technology \\ ${ }^{3}$ Shandong Xiehe University \\ *Corresponding author. Email: han26362@163.com (F.Han); pe_sh@sina.com(S.Peng)
}

\begin{abstract}
To study the similarities and differences of English websites of Chinese and foreign construction multinational companies, six representative multinational companies of construction industry in China and foreign countries were selected as the research objects and named "China group sample" and "foreign group sample". Under the guidance of Eco-translatology theory, the localization strategy of CSCEC English website translation from three aspects of linguistic, cultural and communicative dimensions were feasible, and had a good effect on solving the shortcomings of "China group sample". In the process of website translation, translators should play a central role, actively adapt to the translation ecological environment of the target language, and make a reasonable choice of customization. Based on the theory of Eco-translatology, the research on translation localization strategy of "China group sample" English website was conducted to make up for the lack of research on the localization of English website translation of Chinese construction multinational companies, providing the basic theory for the localization strategy research of this type of multinational enterprise website translation in China.
\end{abstract}

Keywords: Chinese and foreign construction multinational companies, "China group sample", "foreign group sample", Eco-translatologys.

\section{INTRODUCTION}

With the deepening of globalization, many enterprises realize that there are not only language differences between different countries and regions, but also differences in cultural tradition, thinking model consumption concept and so on. Therefore, it is necessary to localize websites to adapt to the language habits, cultural background, customs, consumption concepts and even local laws and regulations of target countries or regions.

Lee believes that commercial websites and advertisements are similar in nature, and advertising translation strategies are closely related to website translation [1]. Sandrini defined the goal of website localization and pointed out that website localization will become a new direction of translation research and translator training [2]. Pym pointed out that the translator should not simply translate according to the fixed source text, but should update or retranslate in time [3]. Chinese scholars began to pay attention to website translation at the beginning of the 21 st century, but they mainly focused on the error analysis of corporate website translation. Miao et al. summarized different arguments on the relationship between localization and translation, and scholars began to pay more attention to the localization of website translation [4]. Wang pointed out the context model proposed by Dell Hathaway [5]. Zhao took Starbucks English websites on both sides of the straits as an example to explore the translation strategies of enterprise websites under the guidance of translation localization [6]. In addition, many scholars have analyzed and discussed corporate website translation from the perspective of different research theories. Chen made a statistical analysis on the literature related to eco translation from 2001 to 2015 [7]. However, domestic and foreign scholars' research on translation localization is basically at the stage of application, and there are few means to 
carry out theoretical analysis with scientific and reasonable concepts [8].

In order to enhance the theoretical nature of translation localization, this paper intends to introduce the concept of Eco-translatology, so as to provide a reasonable theoretical guidance for the localization of website English translation. Then, based on the theory of Eco-translatology, this paper explores the methods to localize the English translation of Chinese enterprise websites.

\section{ANALYSIS ON ENGLISH WEBSITES OF CONSTRUCTIONAL COMPANIES AT HOME AND ABROAD}

\subsection{Research Objects}

On the basis of comprehensive consideration of feasibility and rationality, six multinational companies in construction industry at home and abroad were selected as the research objects, including three domestic companies, namely, China Construction Group Co., Ltd., China Railway Construction Co., Ltd. and China Power Construction Group Co., Ltd.; and three foreign companies, namely Fluor, AECOM and Jacobs. For the convenience of description, the English websites of three domestic companies and three English websites of foreign companies were respectively referred to as "China group sample" and "foreign group sample".

\subsection{Similarities of English Websites of Chinese and Foreign Multinational Construction Companies}

The English website of a construction company is a gateway for enterprises to communicate with customers. It aims to publicize the company's information, products or services by means of marketing, so as to attract customers or potential customers. Based on this, six multinational companies in the construction industry at home and abroad attach great importance to English websites, but their emphasis is slightly different. The common points are: the text information and multimedia information are packaged and delivered to foreign target groups. Through online interaction, customers can receive information and even generate cooperation or purchase motivation. The website is an extremely responsible collection of text, images, applications and multimedia files. In the English websites of the six companies, the same contents include enterprise profile, business scope, talent recruitment, corporate news and social responsibility. Many of the common points are the basic structure of their functions and column elements, which also provide the possibility for the localization construction of Chinese and foreign construction multinational companies.

\subsection{Differences of English Websites of Chinese and Foreign Multinational Construction Companies}

\subsubsection{Differences in Linguistic Level}

Language is not only a tool for human communication, but also a major part of enterprise website construction. Language communication of construction engineering websites is mainly presented in the form of text. Text translation is an important part of website localization [9]. There are many differences between Chinese and English languages. If the translator does not play the initiative of the translator in the translation process and actively adapt to the bilingual translation ecological environment, it will lead to excessive transfer of the characteristics of the original language into the target language, thus resulting in language barriers. This is very obvious in the enterprise profile section of China construction industry website. Capture the "China group sample" and "foreign group sample" part of the enterprise profile.

The number of words on the enterprise profile page of "China group sample" and "foreign group sample" was counted, as shown in Figure 1. It can be seen from Figure 1 that the total number of words in the enterprise profile of "China group sample" was more than that of "foreign group sample"; secondly, the number of words on the enterprise profile page of China Power Construction Group Co., Ltd. was about seven times that of Fluor Company. The comparison shows that the enterprise profile of "China group sample" had heavy reading burden, insufficient emphasis and unclear primary and secondary this kind of problem would hinder the target readers' understanding of the enterprise, and may even restrict the development of "China group sample" in foreign markets. Compared with the "China group sample", the enterprise profile of "foreign group sample" was very concise. Fluor ranked 147 th on the global 500 list and 18th on the list of "the world's most admired companies" in 2017, which shows that there was a simplification method to ensure the double improvement of efficiency and quality. This kind of method provides reference for Chinese constructional multinational companies to stand on the international market better. 


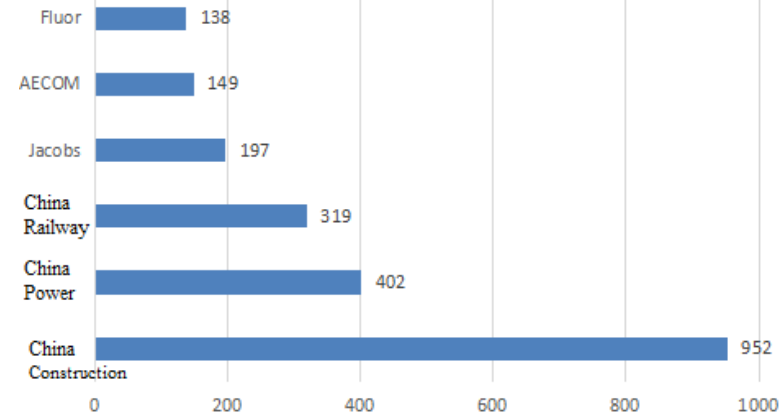

Figure 1 Summary chart of words on enterprise profile page

Comparing the column element names of enterprise English website of "China group sample" and "foreign group sample", it was found that in the same type of column, if the enterprise is different, the name was not exactly the same, which is listed in Table 1. It can be seen from table 1 that in the English expression of the "social responsibility" column, the English names of China Construction Group Co., Ltd. and "foreign group sample" are completely consistent, but the English expressions of the remaining two transnational construction companies of "China group sample" are different, which indicates that the English name of the column of "China group sample" can not be completely consistent with that of the native country, nor can it guarantee that the domestic transnational construction companies can not guarantee the same English name The company's website translation language standardization. One belt, one road, was the only way to localize the language of the "one belt and one way" policy.

It can be seen from table 1 that the English expression of "China group sample" focuses on "social responsibility", while the English expression of "foreign group sample" for "social responsibility" is completely consistent, which shows that the "China group sample" is too perceptual to consider its own operational needs and ignores the standardization of language level. It is very easy for the "China group sample" to express its meaning in international competition and is not conducive to the same type of enterprises Mutual cooperation and assistance. The standardization of language level is the premise to ensure that "five fingers clench the fist" and concentrate on major events. The development mode of "hundred flowers contending and a hundred flowers blooming" may limit the combat effectiveness and vitality of Chinese enterprises in international competition.

\subsubsection{Differences in Cultural Level}

As can be seen, China Electric Power Construction Group Co., Ltd. mainly emphasizes the group's achievements and achievements. Its purpose was to show the group's strong strength and experience in undertaking large-scale or super large-scale projects; fluor mainly emphasizes the technology, professionals and high-tech equipment currently mastered by the company, so as to show the company's high-tech level and undertake various projects China's strong scientific and technological strength. There was no criticism about the two kinds of descriptive armies, which are the embodiment of the cultural customs and thinking habits of the countries where they were located. Foreigners were more direct in expressing their views, and the beauty of implicitness and euphemism was emphasized in China, which makes translators easily encounter obstacles and barriers in translation [10]. The expression of euphemism and implicitness was considered by foreign clients as an expression of self denial or lack of strength, which was not conducive to the survival and development of Chinese construction multinational companies. Therefore, when Chinese construction companies "go out", we can't ignore the cultural differences. We should "go to the mountains and sing what songs" to give foreign customers sufficient cultural and technological confidence, so as to play a positive and positive role in the development of the country.

\subsubsection{Differences in Communication Level}

In order to obtain the usage times of the first person, second person and third person of the two groups of samples, input "we", "our", "us", "you" and "your" respectively to analyze the introduction part in the six websites. It was found that the second person was never been used in the analyzed materials, and the frequency of using first person and the third person was shown in Table 2.

Table 1 English names of the columns "China group sample" and "foreign group sample"

\begin{tabular}{|c|c|}
\hline Corporate & The name of a column \\
\hline $\begin{array}{c}\text { China Construction Group } \\
\text { Co., Ltd. }\end{array}$ & Sustainability/CR \\
\hline $\begin{array}{c}\text { China Railway } \\
\text { Construction Co., Ltd. }\end{array}$ & $\begin{array}{c}\text { Environment Protection } \\
\text { and Social Benefit }\end{array}$ \\
\hline $\begin{array}{c}\text { China Power Construction } \\
\text { Group Co., Ltd. }\end{array}$ & $\begin{array}{c}\text { SUSTAINABLE } \\
\text { DEVELOPMENT }\end{array}$ \\
\hline Fluor & Sustainability \\
\hline AECOM & Sustainability \\
\hline Jacobs & Sustainability \\
\hline
\end{tabular}

Table 2 Personal pronounces in introduction materials

\begin{tabular}{|c|c|c|}
\hline Corporate & First person & Third person \\
\hline $\begin{array}{c}\text { China Construction } \\
\text { Group Co., Ltd. }\end{array}$ & 0 & 20 \\
\hline $\begin{array}{c}\text { China Railway } \\
\text { Construction Co., Ltd. }\end{array}$ & 0 & 9 \\
\hline $\begin{array}{c}\text { China Power } \\
\text { Construction Group Co., } \\
\text { Ltd. }\end{array}$ & 2 & 10 \\
\hline Fluor & 4 & 5 \\
\hline AECOM & 4 & 0 \\
\hline Jacobs & 13 & 2 \\
\hline
\end{tabular}




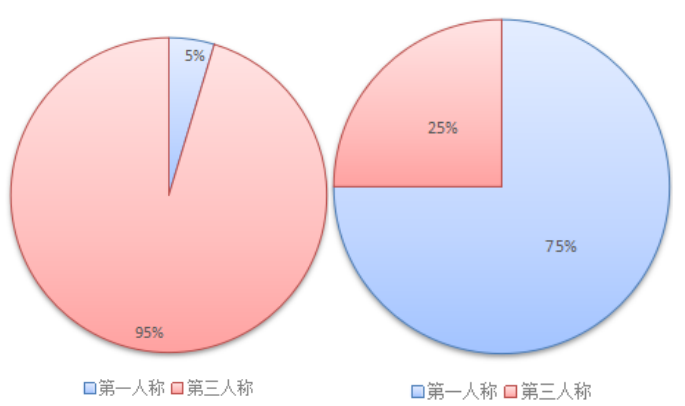

(a) "Chinese group sample" (b) "foreign group sample"

Figure 2 Proportion of first person pronounce and third person pronounce

From Table 2, we can see that the "China group sample" mainly narrates in the third person tone; the foreign group sample uses the first person words such as "we", "our" and "us", and seldom uses the full name of the enterprise in English. In order to further analyze the differences between the two groups of samples, the contents of Table 2 were studied and the proportion pie chart 3 was obtained.

It can be seen from Figure 2 that the proportion of using the first person in the "Chinese group" and "foreign group" was 5\% and $75 \%$ respectively, and the proportion of using the third person is $95 \%$ and $25 \%$ respectively, which indicates that the "China group sample" was good at using the third person, while the "foreign group sample" was good at using the first person. As it happens, the use of the first person can easily shorten the distance between each other, reduce the sense of preparedness, and maximize the sense of participation and satisfaction of the negotiation customers. However, the use of the third person is authoritative and objective, but it was easy to hurt the resonance between customers and was not conducive to narrowing the distance between them. [11] This point was worthy of reference for China's construction multinational companies. The main reason for the difference between the two is that the "China group sample" focuses on the enrichment and fullness of the content, while the "foreign group sample" was very simple.

By March 20, 2020, by comparing the update content frequency of "China group sample" and "foreign group sample", it was found that the update content frequency of "foreign group sample" was low. China Power Construction Group Co., Ltd. updated three times on the same day on June 24, 2013.

In addition, the mood and rhetorical devices of "Chinese group sample" and "foreign group sample" were quite different. The tone of "China group sample" was solemn and objective. There was almost no rhetoric in the whole text, so it maintains a strong objectivity and authority. The "foreign group sample" enterprise language was relatively friendly, and most of them use rhetorical devices. For example, when introducing the business scope, AECOM did not use a lot of professional vocabulary or academic discourse, but lists the construction projects that enterprises participate in and were closely related to people's lives. For example, "designing parks where children play", by depicting the images of parks and children, not only creates a close and relaxed communication atmosphere, but also makes customers naturally think that the enterprise had participated in the construction of the city, contributing to the better life of mankind, and narrowing the distance between enterprises and customers.

\section{TRANSLATION STRATEGIES OF CHINESE MULTINATIONAL CONSTRUCTION CORPORATION WEBSITES}

\subsection{Eco-Translatology Theory}

The process of translation localization of CSCEC's English website was a process in which translators adapt to the translation environment and make choices to better complete translation activities [12]. Ecotranslatology refers to the center of translation activities, which plays a decisive role in the process of translation activities. Translators' translation level and quality had an important impact on the quality of translation. [13-15] Therefore, only when translators play a central role, and comprehensively consider the cultural differences, the ecological environment of website translation, and the needs of enterprises and customers, and strive to achieve the best "integration and adaptation selectivity" in linguistic, cultural and communicative dimensions, could the enterprise English website achieve the best publicity effect.

\subsection{From the Linguistic Dimension}

At the level of linguistic dimensions, the translator adjusts the language form in terms of vocabulary selection and sentence pattern conversion, so as to achieve the best integration and adaptation to the choice transformation. Compared with ordinary text translation, localization translation pays more attention to the flexibility of language structure at the level of language dimension.

\subsection{From the Cultural Dimension}

Chinese and foreign languages and cultures are different, so their nature and content were different. According to eco translatology, translators should adapt to the cultural and ecological environment of the source language and the target language, and pay attention to the transmission of bilingual cultural connotation, so as to avoid customers' misinterpretation of the original meaning from the target culture. The English website of 
Chinese multinational enterprises was one of the important means for China to spread local culture, tradition and values to the world. [16] In the process of website translation, translators need to actively adapt to the cultural system of the whole target language translation ecological environment, so as to avoid the target language customers from misinterpreting or not understanding the translation.

\subsection{From the Communication Dimension}

Eco translatology holds that in the aspect of communication, translators should pay attention to the bilingual communication between the source language and the target language in the process of translation, so as to embody the communicative purpose of the original text in the translation. Corporate publicity was one of the main purposes of corporate websites. The purpose of English websites of Chinese multinational enterprises was to achieve the same or even better communication effect as Chinese websites.

\section{CONCLUSION}

Based on the study of the English websites of six Chinese and foreign construction multinational companies, this paper expounds the success of the "foreign group sample" and the shortcomings of the "China group sample" one by one. Then, this paper discusses the relevant theories of Eco-translatology, and puts forward the localization strategies of English website translation of Chinese construction multinational companies. The conclusions are as follows

(1) Under the guidance of Eco-translatology theory, the localization strategy of CSCEC English website translation from three aspects of linguistic, cultural and communicative dimensions were feasible, and had a good effect on solving the shortcomings of "China group sample".

(2) In the linguistic dimensions, the translator should ensure the accuracy, conciseness and consistency of the language; in the cultural dimensions, the translator should have the awareness of audience, conversion and context; in the communicative dimensions, the translator should pay attention to the customization and communication of the website content.

(3) In the process of website translation, translators should play a central role, actively adapt to the translation ecological environment of the target language, and make a reasonable choice of customization.

(4) Based on the theory of Eco-translatology, "China group sample" English website translation localization strategy research was conducive to make up for the lack of research on the localization of English website translation of Chinese construction multinational companies, and provides the basic theory for the localization strategy research of this type of multinational enterprise website translation in China.

\section{AUTHORS' CONTRIBUTIONS}

H. and S. P. conceived and designed the topics; F. H. wrote the paper and analyzed the data; S. P., D. L., H. B., Y. H. and K. H. collected data.

\section{ACKNOWLEDGMENTS}

This research is funded by 'Youth talent project of scientific research program of Hubei Provincial Department of Education (CN)'- 'China' (Grant No.Q20201101), and their support is gratefully acknowledged. This research is funded by 'College project of teaching and scientific research program of Wuhan College of Arts and Science'- 'China' (Grant No.2020xk19), and their support is gratefully acknowledged.

\section{REFERENCES}

[1] Y. Lee, The Medium Is Global, the Content Is Not: Translating Commercial Websites, in: Networking Knowledge: Journal of the MeCCSA Postgraduate Network, vol. 1, 2009, pp.1-19

[2] P. Sandrini, Website Localization and Translation, in: In G. A. Heidrun \& N. Sandra (Eds), Multidimensional Translation: Challenges of Multidimensional Translation Proceedings of EUHLSC, Saarbrucke: Advanced Translation Research Center, Saarland University, 2005, pp. 122-134

[3] A. Pym, Website Localization, in: In K. Malmkjar \& K. Windle (eds), The Oxford Handbook of Translation Studies, Oxford: Oxford University Press, 2011, pp. 89-112

[4] J. Miao, L. Zhu. Localized Training as an Indispensable Element of Translation Curriculum, in: Chinese Translators Journal, vol. 5, 2008, pp. 30-34, DOI: 1000-873X (2008)05-0030-05

[5] W. J. Wang, Cultural Adaption Strategies onLocalization of Website Translation, in: Net Friend World, vol. 8, 2014, pp. 24-25

[6] Y. Zhao, On Translation Localization of Company Websites, in: Journal of Wuyi University, vol. 7, 2016, pp. 55-58

[7] S. B. Chen, Analysis on the References about Ecotranslatology during Fifteen Years, in: Shanghai Journal of Translators, vol.5, 2017, pp. 6-9 
[8] Y. Y. Huang. The Belt and Road and Translation, in: Shanghai Journal of Translators, vol. 3, 2017, pp. 1-3, DOI: 1672-9358(2017)03-0001-03

[9] H. B. Song, D. L. Geng, Linguistic Deviations in Cyber Context, in: Product Safety and Recall, vol. 2, 2006, pp. 21-23

[10] X. B. Yang. Mistranslation Criticism of Companies' English Websites, in: Chinese Science and Technology Translators Journal, vol. 20, 2007, pp. 1-4.

[11] J. C. Yu. On Characteristics of the Translation of News Report, in: Shanghai Journal of Translators, vol.3, 2001, pp. 25-27. DOI: 1672-9358(2008)020001-05

[12] F. P. Yu. The "Turns" in Current Translation Studies, in: Foreign Languages and Their Teaching, vol. 2, 2012, pp. 78-81, DOI: 1004-6038(2012)020078-04
[13] G. S. Hu. Eco-translatology: Research Foci and Theoretical Tenets, in: Chinese Translators Journal, vol. 2, 2011, pp.5-9. DOI: 1000-873X (2011) 020005-05

[14] G. S. Hu. Eco-translatology: A Primer, in: Chinese Translators Journal, vol. 6, 2008, pp. 11-15. DOI: 1000-873X (2008)06-0011-05

[15] G. S. Hu. An Approach to Translator an Adaptation and Selection, Hubei Education Press, 2004.

[16] Q. Shao. Methods to Improve Brand Asset Efficiency through Company's Website, in: News World, vol. 6, 2013, pp. 152-154. 